\title{
The impact of ISO/TS 16949 on automotive industries and created organizational capabilities from its implementation
}

\author{
Bakhtiar Ostadi, Mohammad Aghdasi, Reza Baradaran Kazemzadeh \\ Department of Industrial Engineering, Faculty of Engineering, Tarbiat Modares University (IRAN) \\ bostadi@modares.ac.ir; aghdasim@modares.ac.ir;rkazem@modares.ac.ir
}

Received November 2009

Accepted September 2010

\begin{abstract}
ISO/TS 16949 is an ISO Technical Specification. ISO/TS 16949 achieves the objectives which are continually to improve the production of automobile parts and related services, and to strengthen the international competition for the automotive industry and its suppliers. By applying this quality system standard, automotive manufacturers could offer superior products and good services to customers. The more the companies know about the benefits if quality management systems such as ISO/TS 16949, better they can seek interest and determine indices of these systems. So, this standard has been implemented in companies considering a number of benefits. In this paper, we carry out an empirical study in order to verify the importance these benefits and ranking them based on the value of importance. Finally, the study tends to provide a reference guide considering benefits assessment and created organizational capabilities from this standard for the automotive industry in pursuing ISO/TS 16949 and procuring maximum benefit from the results.
\end{abstract}

Keywords: ISO TS/16949, quality management system, assessment, organizational capabilities 


\section{Introduction}

\subsection{ISO/ TS 16949:2009}

In recent years, the importance lent to quality management, both in Total Quality Management (TQM) models and in ISO 9000 normalization and certification, has been overwhelming in the business world (Easton \& Jarrel, 1998; Lee \& Palmer, 1999; Koc, 2007; Ahire \& Ravichandran, 2001). This has led to a numerous researchers to concentrate their efforts on studying the quality movement.

Currently, there are several quality management strategies or philosophies that an organization can apply to maintain and improve quality of its processes, products, services and overall business performances. The most important of them are:

- $\quad$ total quality management (TQM);

- the Malcolm Baldrige Criteria for Performance Excellence;

- the EFQM Excellence Model; and

- the standard ISO 9001.

ISO 9000 can be considered to be a subset of TQM. ISO 9000 mainly deals with quality management systems (QMSs) for the design, development, purchasing, production, installation, and servicing of products and services. The literature does not have unanimous agreement on the effects of ISO 9000 registration on organizational performance. Some of the previous studies found that ISO registration did not necessarily improve companies' performance (Sila, 2007). On the other hand, according to the International Organization for Standardization, ISO 9000 can increase customer satisfaction, provide cost and risk-management benefits, and result in improved competitiveness (Sila, 2007). In fact, Rao, Raghunathan and Solis (1997) found that ISO-registered companies had better quality management practices and quality results than those companies that were neither ISO-registered nor interested in obtaining registration. Ismail and Hashmi (1999) also reported better performance for ISO-registered companies compared to non-ISO-registered companies.

ISO 9000 provides the opportunity to evaluate suppliers' goods and services consistently. Many independent third parties or registrars are now using the ISO 
9000 series standards to evaluate suppliers' quality systems. When a supplier's quality system conforms to the appropriate ISO 9000 standards, the registrar issues the supplier a certificate. The supplier is also listed in directories of registered suppliers (Lee \& Palmer, 1999; Koc, 2007; Rao et al., 1997).

ISO/TS 16949 is a standard for QMS. This standard outlines the specific requirements for the application of ISO 9001:2008 to automotive production and relevant service part organizations. It contains recommended automotive industry practices and examples. ISO 9001:2008 specifies requirements for a QMS that can be used for internal application by organizations, or for certification, or for contractual purposes. Both standards use the "process" approach, referring to the application of a system of processes (numerous linked activities) that allows the transformation of inputs into outputs, such as in the manufacture of cars and related parts. ISO/TS 16949 is developed by the International Automotive Task Force (IATF) for global recognition; it has become a mandatory set of requirements of many automotive Original Equipment Manufacturers (OEMs) in North America and Europe (ISO/TS 16949:2009; Lin, Liu, Hsu, \& Lai, 2004).

This standard recognizes the uniqueness of every automotive supplier's process, while providing critical tools to help your company better meet customer-specific requirements. Rather than using the "element" or checklist method of the QS-9000 standard, ISO/TS 16949:2009 is based on the process approach. It provides an organized way for business to document and codify specific work practices in ways that best serve customer needs (ISO/TS 16949: 2009).

ISO/TS 16949 eliminates redundancy, cost and administrative burdens imposed by multiple standard formerly mandated in various geographic regions. It will ultimately replace QS-9000 and European quality management standards for most North American and European Quality Environment Modules (QEMs) by the end of 2006 due to mandates by major automotive OEMs (Lin et al., 2004; Bayati \& Taghavi, 2007).

This paper consists of two sections. The first section comes with the statistical results of surveys of one of the biggest automotive industry in the Middle East that have failed and succeeded in ISO/TS 16949. Furthermore, the performances after executing ISO/TS 16949 were evaluated by assessment formula which it has been developed based on the refined benefits and defined factors. This formula can be 
used by firms to analyze their status in achieved benefits during implementing ISO/TS 16949 in their organizations. Despite the importance of quality managements systems such ISO/TS 16949, research on created organizational capabilities form benefits and results of these systems is not yet firmly established or well structured. Nonetheless, it is difficult to say what the organizational capabilities are which QMSs such as ISO/TS 16949 created (discussed). Therefore, the second section establishes and examines created organizational capabilities from this quality management system.

\subsection{QMSs in I ran: historical perspective}

Quality tendency and movements can be seen in the majority of Iranian companies, and the preference is to acquire ISO 9000 certification (Bayati \& Taghavi, 2007). The main reason for companies to get this certification is to compete in trade and achieve better sale through inducing products quality. Quality management initiatives did not start in Iran until the end of the 1980's. The first five-year economic development program, which began in 1989, was the main driver for emphasis on quality in the country. The initiatives began by presenting workshops on quality management and quality assurance in a governmental institution, the Industrial Management Institute (IMI). Also, economic relationships with certain European countries (such as Germany, France, Italy) were key reasons for the application of ISO 9000 standards in Iran. This movement urged companies to practice quality management through the implementation of ISO 9000 standard (Amiran, 2000; Mellat Parast, 2006).

The first movement in this regard, started with collaboration with Peugeot (Citroen). The two corporations, Iran Khodro and Citroen, signed a contract to produce Peugeot in Iran. Along with that, KIA Motors Company, from South Korea, established a production line in Iran. It was during that period that QS-9000 standards were developed and internalized in the automotive industry in Iran. This trend encouraged consulting firms to seek more business opportunities for the automotive part makers, to the extent that some of them changed their business strategy and mainly focused on the consulting industry (Bayati \& Taghavi, 2007; Amiran, 2000; Mellat Parast, 2006).

The second movement toward quality management began around 1993, having its origin in the automotive industry. The automotive industry in I ran was established 
around 1960, but its technological capacity was not developed far beyond assembly and maintenance. There was a national interest (mostly among the policy makers) for further developing of this industry. The government decided to restructure the automotive industry, which was mainly integrated. The strategy was to disintegrate it, to provide the required infrastructure for it, and finally to develop the national automobile. Thus, the government began to invest in the automotive industry (labor, capital), collaborating with a few European countries (France, Germany), and provided financial/technical support for the automotive part makers (Bayati \& Taghavi, 2007; Amiran, 2000; Mellat Parast, 2006).

\section{Design and method of experiment}

In order to explore the effects of ISO/TS benefits on Iran corporations, a survey questionnaire was mailed to 57 registered companies. The questionnaires are design with reference to Lin et al. (2004), Shih, Huarng, and Lin (1996) and Lou (1997), as well as some advice from the project leaders of several interviewed companies and consultants from some consulting companies. In order to measure all items, a five-point Likert scale has been used. The scale ranged from 1 to 5 , indicating [1] = Very Low, [2] = Low, [3] = Medium, [4] = High, and [5] = Very High.

Due to the structure of the study, SPSS 13.0 for Windows is used in all the statistical analysis. The analysis methods include: t-test (for independent samples was used to evaluate the statistical significance of the difference), factor analysis, and cluster analysis.

\section{Results and discussions}

\subsection{Demographic information}

In order to explore the effects of ISO/TS 16949 motivations and benefits in Iran corporations, a survey questionnaire was mailed to 57 registered companies. In the sample $100 \%$ of the participants were male. This gender homogeneity was not unusual since most managers and consultants at that level in I ran are male. The average age for the respondents was 49 years. All respondents have been in the automotive industry for at least five years. 
The questionnaire was designed and pre-tested by two academicians and three ISO managers of certified companies. The managers who are responsible for implementing ISO/TS 16949 are asked to answer subjectively questions about the degree of benefit from certification and the motivations of their companies to certification.

\subsection{T-test}

All data were collected. Thirty-five questions about the benefits of ISO/TS 16949 implementation are measured in Likert scale of five points. Writing a 5 means that the ISO manager agrees great benefits from ISO certification, and writing a 1 means little help from ISO certification. Of 57 mailed questionnaires, 39 were returned by respondents for about a $68 \%$ rate of return. Three of the 39 returned questionnaires were incomplete. This study, therefore, is based on 36 completed questionnaires. Table 1 presents the distribution of the respondents by firm size.

\begin{tabular}{|c|c|c|c|}
\hline Number of employee & Number of company & $\%$ & $\%$ Cumulative \\
\hline $0 \leq$ No. $\leq 25$ & 17 & 47.2 & 47.2 \\
$25 \leq$ No. $\leq 50$ & 15 & 41.7 & 88.9 \\
$50 \leq$ No. $\leq 75$ & 2 & 5.55 & 94.4 \\
$75 \leq$ No. $\leq 100$ & 2 & 5.55 & 100 \\
\hline
\end{tabular}

Table 1. "The distribution of the respondents by firm size".

Table 2 shows companies' motives for implementing ISO/TS 16949:2002. Most of the companies choose "improve company quality image" (78\%), "strengthen quality management system" (69\%), "upgrade product, service \& market share" (42\%) and "Integrates ISO/TS 16949 with TQM" (47\%) as their motivation for implementing ISO (51\%).

\begin{tabular}{|c|c|}
\hline Motives & Percentage \\
\hline Improve company quality image & 0.78 \\
Upgrade product, service \& market share & 0.42 \\
Strengthen quality management system & 0.69 \\
Integrates ISO/TS 16949 with TQM & 0.47 \\
\hline
\end{tabular}

Table 2. "Motives for implementing ISO/TS 16949".

The null hypothesis of $\mathrm{HO}$ is assumed, that the average score of degree of benefit is 3 , and the alternative hypothesis of $\mathrm{HI}$ is assumed to be that the average score of degree of benefit is greater than 3 . The t- test is used for testing $\mathrm{H} 1$, and the results of t-tests for each item are shown in Table 3. All tests were performed at a $90 \%$ confidence level (alpha $=0.1$ ). The value of Cronbach coefficient alpha for 
those 36 items is 0.977. According to Guieford (1965), a reliability coefficient (Cronbach's a) greater than 0.7 , indicates a high reliability; while values between 0.35 and 0.7 are considered fair. Thus, the reliability of the results from the questionnaire is highly stable and consistent.

\begin{tabular}{|c|c|c|c|c|}
\hline \multicolumn{2}{|r|}{ I tem name } & \multirow{2}{*}{$\begin{array}{c}\begin{array}{c}\text { Standard } \\
\text { deviation }\end{array} \\
0.9063\end{array}$} & \multirow{2}{*}{$\begin{array}{c}\begin{array}{c}\text { t } \\
\text { value }\end{array} \\
4.987\end{array}$} & \multirow{2}{*}{$\frac{\text { Sign. }}{Y}$} \\
\hline Q1 & Jobs assign are clear and reasonable & & & \\
\hline Q2 & Authorities and responsibilities are committed to paper & 0.9568 & 7.647 & Y \\
\hline Q3 & Higher level managers are clearer with the internal operation & 0.9422 & 4.684 & Y \\
\hline Q4 & Base employees are clearer with the internal operation & 0.9718 & 5.987 & Y \\
\hline Q5 & $\begin{array}{l}\text { Managing of the laboratory is more specific after } \\
\text { implementation of ISO/TS. }\end{array}$ & 0.8764 & 6.244 & Y \\
\hline Q6 & $\begin{array}{l}\text { Managers support the process and idea of their subordinate } \\
\text { employees }\end{array}$ & 0.9942 & 5.648 & Y \\
\hline Q7 & Executive level encourage their employees to express their & 0.9718 & 3.540 & Y \\
\hline Q8 & ideas & 0.8863 & 4.173 & Y \\
\hline Q9 & High loyalty to the company among colleagues & 1.0397 & 0.637 & $\mathrm{~N}$ \\
\hline Q10 & Reducing management cost & 0.9557 & 1.463 & $\mathrm{~N}$ \\
\hline Q11 & Reducing quality cost & 0.9435 & -0.98 & $\mathrm{~N}$ \\
\hline Q12 & Decrease in purchasing cost & 0.9449 & 1.571 & $\mathrm{~N}$ \\
\hline Q13 & Reduction of production cost & 0.9195 & 4.528 & Y \\
\hline Q14 & Decreasing the defect rate of production & 1.0151 & 2.877 & Y \\
\hline Q15 & Trust and care among colleagues & 0.9627 & 2.062 & Y \\
\hline Q16 & Manager and subordinates are related happily & 0.9476 & 6.837 & Y \\
\hline Q17 & Increase the morality of the organization & 1.0309 & 6.499 & Y \\
\hline Q18 & $\begin{array}{l}\text { Increase of communication between departments } \\
\text { Improvement of communication between departments and }\end{array}$ & 0.9381 & 4.053 & Y \\
\hline Q19 & higher level & 1.0108 & 5.550 & Y \\
\hline Q20 & Improvement of communication and cooperation between & $\begin{array}{l}1.0100 \\
0.9442\end{array}$ & 1.967 & $\mathrm{~N}$ \\
\hline Q21 & department and colleagues & 0.8930 & 2.619 & Y \\
\hline Q22 & Decrease of stock inventory & 0.9664 & 2.654 & Y \\
\hline Q23 & Increasing production capacity & 1.0673 & 2.729 & Y \\
\hline Q24 & Reduction of cycle time & 1.0237 & 8.149 & Y \\
\hline Q25 & Significant improvement on the efficiency of a job & 0.9270 & 0.742 & $\mathrm{~N}$ \\
\hline Q26 & Increase of customers satisfaction & 0.9860 & 1.866 & $\mathrm{~N}$ \\
\hline Q27 & Increase of profits & 0.9559 & 6.247 & Y \\
\hline Q28 & Increasing orders & 0.9359 & 7.126 & Y \\
\hline Q29 & Everyone is clearer to the internal information transfer and & 1.0003 & 3.039 & Y \\
\hline Q30 & changes & 0.9940 & 4.514 & Y \\
\hline Q31 & Documentation is complete and reasonable & 1.0496 & 3.786 & Y \\
\hline & Less backlog of missive and related document & 1.0166 & 6.244 & Y \\
\hline Q32 & $\begin{array}{l}\text { Less un-integrated related documents between departments } \\
\text { Smoother transaction due to simplified and integrating }\end{array}$ & & & \\
\hline Q33 & document & 0.9654 & 1.430 & $\mathrm{~N}$ \\
\hline Q34 & More advantageous than disadvantageous of the simplified and & 0.8943 & 2.618 & $\mathrm{Y}$ \\
\hline Q35 & $\begin{array}{l}\text { integrating document. } \\
\text { Sufficient people in understanding related information about } \\
\text { ISO/TS. } \\
\text { Sufficient understanding of quality related statistical } \\
\text { techniques. } \\
\text { Training programs are held frequently }\end{array}$ & 0.9023 & 4.328 & Y \\
\hline
\end{tabular}

Table 3. "Benefits of ISO/TS 16949".

As shown in Table 3, "Authorities and responsibilities are committed to paper", "Increase of customers' satisfaction" and "Documentation is complete and reasonable" are the three factors that have the most effect on efficiency after the 
implementation of ISO/TS 16949. On the other hand, factors such as "Decrease in purchasing cost", "Reducing management cost", "Increase of profits", "Reducing quality cost", "Sufficient people in understanding related information about ISO/TS", 'Reduction of production cost', 'Increasing orders' and 'Decrease of stock inventory' are the least significant factors after the t-test.

The results show that the t-tests fail to reject the null hypotheses for items Q9, Q10, Q11, Q12, Q20, Q25, Q26 and Q33. In other words, the benefits of these items are not significant. The benefits of the remaining 27 items are recognized to be significant. Hence, a lot of beneficial items are obtained by ISO/TS implementation. These benefits are quite obvious.

\subsection{Factor analysis}

The 27 beneficial items were reorganized into six common factors using factor analysis. The principle component analysis method was employed. Six common factors are chosen to explain the $74.82 \%$ of the variances of the 27 items since each of their corresponding eigen values is greater than one. Interpreting based on the factor loading pattern of the unrotated factor matrix would be difficult.

\begin{tabular}{|c|c|c|c|c|c|c|}
\hline Item & Factor1 & Factor2 & Factor3 & Factor4 & Factor5 & Factor6 \\
\hline Q19 & 0.718 & - & - & - & - & - \\
Q18 & 0.721 & - & - & - & - & - \\
Q17 & 0.699 & - & - & - & - & - \\
Q16 & 0.651 & - & - & - & - & - \\
Q27 & 0.479 & - & - & - & - & - \\
Q24 & 0.477 & - & - & - & - & - \\
Q22 & - & 0.786 & - & - & - & - \\
Q23 & - & 0.683 & - & - & - & - \\
Q29 & - & 0.646 & - & - & - & - \\
Q4 & - & 0.347 & - & - & - & - \\
Q14 & - & - & 0.722 & - & - & - \\
Q7 & - & - & 0.714 & - & - & - \\
Q15 & - & - & 0.687 & - & - & - \\
Q6 & - & - & 0.579 & - & - & - \\
Q34 & - & - & 0.519 & - & - & - \\
Q21 & - & - & 0.449 & - & - & - \\
Q5 & - & - & - & -.768 & - & - \\
Q1 & - & - & - & 0.708 & - & - \\
Q2 & - & - & - & -.678 & - & - \\
Q3 & - & - & - & 0.612 & - & - \\
Q32 & - & - & - & - & 0.794 & - \\
Q31 & - & - & - & - & 0.658 & - \\
Q35 & - & - & - & - & - & - \\
Q30 & - & - & - & - & - & 0.537 \\
Q8 & - & - & - & - & - & 0.487 \\
Q28 & - & - & & & \\
\hline
\end{tabular}

Table 4. "Equamax rotation component analysis factor matrix". 
The equamax rotation method is used to obtain easier explanations of six factors. The equamax rotation component analysis factor matrix is shown in Table 4 . Those factor loadings whose values are lower than 0.4 are ignored. Note that the total amount of extracted variance is the same in the rotated solution as it was in the unrotated one. The variance explained by each factor ranges from 4.53 to 3.80 . The explanatory power has been distributed more evenly owing to the rotation. The name of each common factor is given on the basis of the factor loading.

Six common factors were named: (a) Communication; (b) Integration; (c) Status of organization; (d) Managing Aspect; (e) Documentation; and (f) Managing efficiency. Thus, the answers given by respondents to the 35 benefits of ISO/TS implementation a more manageable and significant six-factor structure, showing six dimensions of the benefits created by a this quality management system. The most important part is documentation. The least important benefit is managing efficiency, whereas managing aspect and integration have an average importance. This proves that ISO generate mainly documentation and many certified firms have to improve employee involvement through enhancing the communication.

\subsection{Cluster analysis}

Cluster analysis is a group of multivariate techniques whose primary purpose is to assemble objects based on the characteristics they possess. Cluster analysis classifies objects, so that each object is similar to the others in the cluster with respect to a predetermined selection criterion. The resulting clusters of objects should then exhibit high internal (within-cluster) homogeneity and high external (between clusters) heterogeneity. By applying this analysis, we use the factor scores in previous analysis and we group corporations according to their benefits of ISO/TS.

According to the theory of task motivation and incentives of Locke (1968) and Locke, Shaw, Saari and Latham (1981), this survey is conducted to verify how motivations affect Iran corporate performances, which are the benefits of the ISO/TS 16949 implementation. Based on their motivation, the 36 sample corporations are classified into four clusters using cluster analysis. Table 5 shows the number of corporations which choosing each motivation in each group. Multivariate analysis of variance (MANOVA) is used to test the effects of different patterns of motivation on benefits of the ISO/TS 16949 implementation. The six 
factors from Table 4 are chosen as dependent variables, and the patterns of motivation form the independent variable.

\begin{tabular}{|l|c|c|c|c|}
\hline \multicolumn{1}{|c|}{ Motives } & Group 1 & Group 2 & Group 3 & Group 4 \\
(2) & (3) & $\begin{array}{c}\text { (8) } \\
\text { (23) }\end{array}$ \\
\hline Improve company quality image & 2 & 0 & 7 & 19 \\
Upgrade product, service \& market share & 2 & 2 & 0 & 15 \\
Strengthen quality management system & 3 & 0 & 8 & 12 \\
Integrates ISO/TS 16949 with TQM & 0 & 0 & 4 & 18 \\
\hline
\end{tabular}

Table 5. "The number of corporations choosing each motivation in each cluster".

The results of the MANOVA are shown in Table 6 . Since the p-value of Wilks's lambda is less than 0.1 (alpha is set to 0.1 ), the global benefits of the ISO/TS 16949 implementation are different among different patterns of motivations. Specifically, the benefits on "Communication" and "Managing efficiency" are different (the p-values of factor 1 and factor 6 are both less than 0.1 ).

Duncan's multiple range test is used to compare the means of benefits on "Communication" and "Managing efficiency". The average scores on factor 1 are $3.79,2.21,3.23$ and 3.69 for each group respectively. The average scores on factor 6 for each group in ascending order are 4.00, 2.79, 3.64 and 4.01. The results show that group 1 and group 4 obtained stronger help on both "Communication" and "Managing efficiency" than group 2 did.

\begin{tabular}{|l|c|c|}
\hline \multicolumn{1}{|c|}{ Item } & F-value & P-value \\
\hline Factor 1 & 2.78 & 0.413 \\
Factor 2 & 1.92 & 0.159 \\
Factor 3 & 1.04 & 0.4132 \\
Factor 4 & 0.71 & 0.643 \\
Factor 5 & 0.12 & 0.899 \\
Factor 6 & 2.61 & 0.045 \\
\hline Statistic & F-value & P-value \\
Wilks's lambda & 1.6498 & 0.0231 \\
Pillai's trace & 1.4997 & 0.0331 \\
Hotelling-Lawley trace & 1.7923 & 0.0144 \\
Roy's greatest root & 5.8769 & 0.0002 \\
\hline
\end{tabular}

Table 6. "The results of MANOVA".

The effects of incentives are statistically significant. Group 2 is the most passive; the employees of group 2 just acted on order without any pressure from their customers. Hence, the benefits of ISO/TS implementation are least for group 2 . In other words, the companies in group 2 might just want to obtain the ISO/TS certification without the intention of achieving continuous quality improvement. 


\section{Assessment of ISO/ TS 16949 implementation considering its benefits}

The extracted benefits can be used for the assessment and comparison of auditing of the considered organizations with measurement of the indicators and applying their weights and also dimensions' weights. For achieving this goal, we can set a question which it is titled "please assess the strength of each benefits which achieved form implementing of ISO/TS 16949 in your company and assign a number between 1 to 10 to them".

Simple statistical calculations were used for evaluating the benefits (indicators). Elements were scored in the range of ten to one. Each significant element had equal weight. We can use equation 1 to measure the ISO/TS 16949 implementation and achieved benefits within each organization. Here W shows weight of factors $(\mathrm{Wd})$ and the BENdi is average value of each benefits. After calculating the above formula for each company we will have:

$$
I S O / T S \text { Assesment }=\sum_{d=1}^{6} \sum_{i=1}^{i_{d}} W_{d} \cdot B E N_{d i}
$$

\section{Discussion and conclusions}

\subsection{Theoretical implications}

The objectives of this paper are as follows:

- to extract the most important benefits and motives of ISO/TS implementation;

- to establish managerial factors for 35 listed benefits by factor analysis;

- to propose a assessment framework that can be used by firms to analyze the value of achieved benefits in their organization after implementing ISO/TS;

- to introduce created organizational capabilities from implementation of quality management system in accordance with ISO/TS 16949;

- to map the six managerial factors into COC-QMs. 
In measuring the ISO/TS 16949 benefits, firstly, we asked the respondents to choose the motivations of their companies to ISO/TS 16949 certification among the 4 listed motives for implementing ISO/TS 16949. Secondly, we asked respondents to rate the effect ISO/TS 16949 had on the 35 listed benefits on a five-point scale, ranging from 1 to 5 . The rating did not say anything about whether the respondent regarded his organisation as being strong or weak in the 35 proposed areas (an assessment framework for measuring the state of organization, as being strong or weak in the 35 proposed benefits, has been proposed in section 4). It aimed at assessing the achieved benefits of ISO/TS 16949 regardless of the organization's previous level of performance.

The findings of the study also show a statistical relation between many of the ISO/TS efforts and benefits. The empirical results indicate that adopting ISO brings registered Iran plants significant help in enhancing status of organization, systemization with good documents and data, better quality control, increased competing ability in sales, verifying the internal auditing system and clear managing aspect and efficiency. The effects of incentives on the benefits from ISO are also statistically significant. With more positive attitudes, implementing ISO could bring companies more help in enhancing status of organization and clear managing aspect and efficiency (See Table 3).

Having the results of the analysis, we can conclude that (1) the highest motive of the implementation of the ISO/TS 16949 quality system is the requisition of the higher executive level, which means that the attitude to implementation of the ISO/TS 16949 quality system is highly positive; (2) There is no relative increase of employees' understanding about ISO/TS 16949 quality system after the approval of ISO/TS 16949 quality system certification; (3) The higher the internal efficiency level, the higher the level of satisfaction to the internal efficiency after the implementation of ISO/TS 16949; (4) The higher the managing efficiency level, the higher the level of satisfaction to the internal efficiency after the implementation of ISO/TS 16949. 


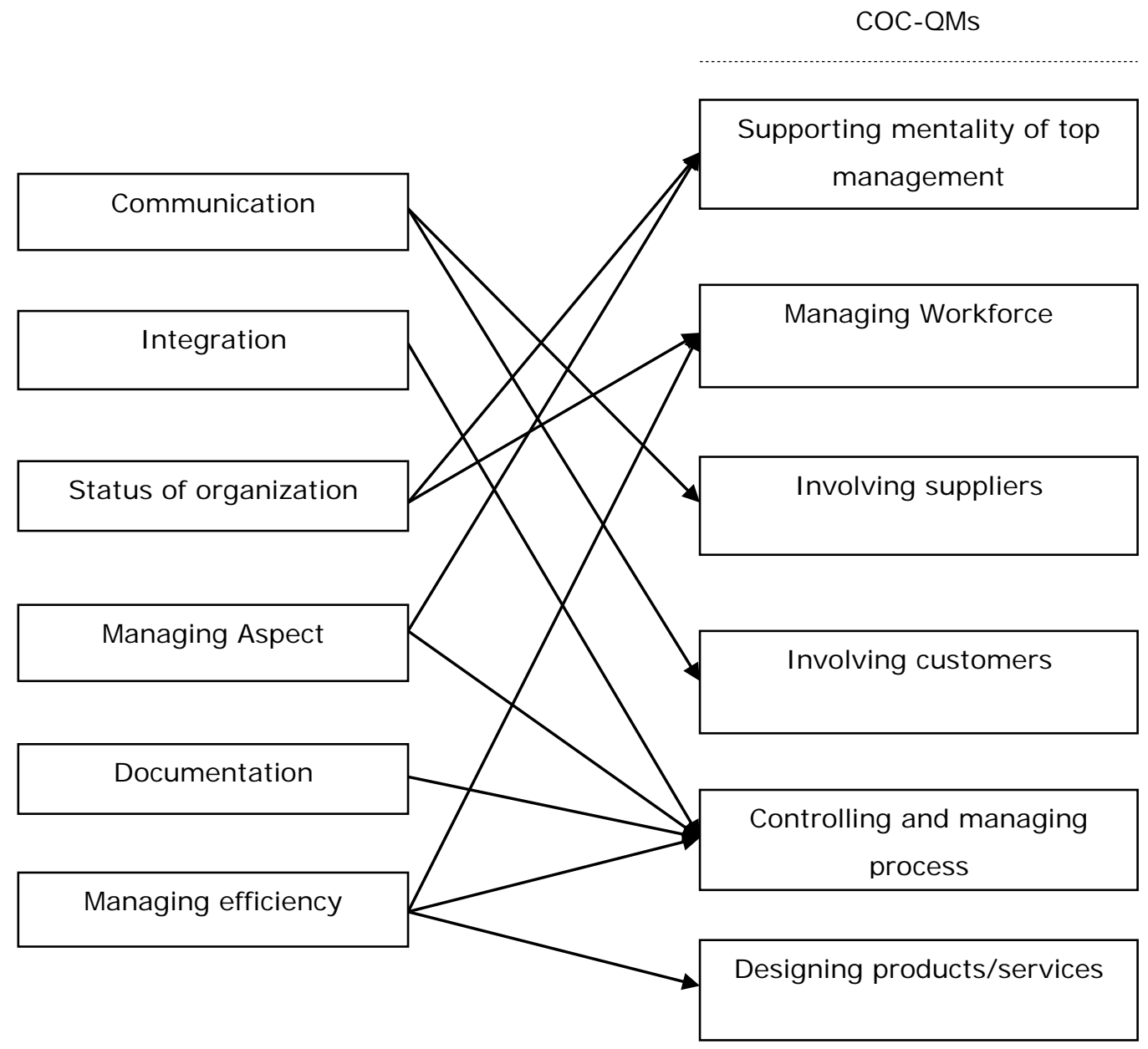

Figure 1. "Created organizational capabilities from implementation of quality management system (COC-QMs)".

Capabilities, thus, refer to an organization's ability to assemble, integrate, and deploy valued resources, usually, in combination or co presence (Amit \& Schoemaker, 1993; Schendel, 1994; Russo \& Fouts, 1997). Capabilities subsume the notion of organizational competence (Prahalad \& Hamel, 1990) and are rooted in processes and business routines. Generally, it can be concluded that these benefits can be created or enhanced the organizational capabilities. In order to assess beneficial items, assessment formula (Eq. 1) which it has been developed based on the refined benefits and defined factors, can be used by organizations to assess their status in achieved benefits and created organizational capabilities by these achievement during implementing ISO/TS 16949 in their organizations. Figure 1 are shown the organizational capabilities. It is clear that the more the value of benefits' assessment (Eq. 1) these capabilities also will be stronger. 


\subsection{Managerial implications}

The study has shown that (1) there is a statistical relation between ISO/TS effort and implementing benefits; and (2) successful implementation of ISO/TS lead to create some important organizational capabilities which value of this capabilities are related to the value of successful quality efforts. Thus, it seems that the most important task for quality managers and indeed for top management is to make these values permeate their organisation. The QMS literature has unanimously emphasized the importance of top management support for QMS (Beer, 2003; Yeung, Cheng, \& Lai, 2005). This study once again confirms that "supporting mentality of top management", "Managing Workforce", "Involving suppliers", "Involving customers", "Controlling and managing process", and "Designing products/services" are critical capabilities which they have been achieved from implementing the QMS (such as ISO/TS) and they are also important for future improvement projects in each company.

\subsection{Limitations}

Several limitations of this study should be discussed in this section. First, the data collection method was based on managers' respond. Managers response to questionnaires from their own local environment, which may or may not reflect what is going on in the organization as a whole (Lakhal, Pasin, \& Limam, 2006). Nevertheless, the use of manager's respond is frequently used in quality management research (Madu, 1998). Second, the study's sample size is small. Hofstede, Neuijen, Ohayv and Sanders (1990) state that a lower sample size is acceptable when this kind of stable data with high internal consistency is used. The results of this study should not be generalized beyond what is reasonable, given the nature of the sample. Future studies should consider substantially larger samples including greater representation of industries and countries.

\subsection{Future research}

Future research can be done to explain the barriers in adoption or the reasons why firms are reluctant to adopt the quality management standards. The relationship between the technology level of manufacturing systems and ISO/TS 16949 practices is also an interesting subject to investigate. In addition, how the commitment is achieved within the firm as well as additional tools and techniques 
that support the certification are important criteria to investigate in future research. It would also be interesting to investigate the benefits of ISO/TS 16949 in a cross-national research.

\section{References}

Ahire, S., \& Ravichandran, T. (2001). An Innovation Diffusion Model of TQM Implementation. IEEE Technology Engineering Management, 48(4), 445-464. doi: $10.1109 / 17.969423$

Amiran, H. (2000). Designing of Evaluation Method to Impacts of Performing Quality Assurance Systems in Automotive Industries. Master Thesis, Science and Researches Branch of Azad University, Tehran.

Amit, R., \& Schoemaker, P.H. (1993). Strategic assets and organizational rent. Strategic Management Journal, 14(1), 33-46.

doi: $10.1002 / \mathrm{smj} .4250140105$

Bayati, A., \& Taghavi, A. (2007). The impacts of acquiring ISO 9000 certification on the performance of SMEs in Tehran. The TQM Magazine, 19(2), 140-149. doi: $10.1108 / 09544780710729980$

Beer, M. (2003). Why total quality management programs do not persist: The role of management quality and implications for leading a TQM transformation. Decision Sciences, 34, 623-642.

doi: 10.1111/j.1540-5414.2003.02640.x

Easton, G.S., \& Jarrel, S.L. (1998). The effect of total quality management on corporate performance: an empirical investigation. Journal of Business, 71(2), 253-307.

\section{doi: $10.1086 / 209744$}

Guieford, J.P. (1965). Fundamental Statistics in Psychology and Education, 4th edn. New York: McGraw-Hill.

Hofstede, G., Neuijen, B., Ohayv, D.D., \& Sanders, G. (1990). Measuring organizational cultures: a qualitative and quantitative study across twenty cases. 
Administrative Science Quarterly, 135, 286-316.

doi: $10.2307 / 2393392$

Ismail, M.Y., \& Hashmi, M.S.J., (1999). The state of quality management in the Irish manufacturing industry. Total Quality Management, 10(6), 853-862.

ISO/TS 16949:2009, Quality management systems -- Particular requirements for the application of ISO 9001:2008 for automotive production and relevant service part organizations

Koc, T. (2007). The impact of ISO 9000 quality management systems on manufacturing. Journal Material Process Technology, 186(1-3), 207-213. doi: 10.1016/j.jmatprotec. 2006.12.034

Lakhal, L., Pasin, F., \& Limam, M. (2006). Quality management practices and their impact on performance. International J ournal of Quality \& Reliability Management, 23(6), 625-646.

doi: $10.1108 / 02656710610672461$

Lee, K.S., \& Palmer, E. (1999). An empirical examination of ISO 9000 registered companies in New Zealand. Total Quality Management, 10(6), 887-899.

Lin, W.-T., Liu, C.-H., Hsu, I-C., \& Lai, C.-T. (2004). An Empirical Study of QS 9000 in the Automobile and Related Industries in Taiwan. Total Quality Management, 15(3), 355-378.

Locke, E.A. (1968). Toward a theory of task motivation and incentives. Organizational Behavior and Human Performance, 3(2), 157-189.

doi: 10.1016/0030-5073(68)90004-4

Locke, E.A., Shaw, K.N., Saari, L.M., \& Latham, G.P. (1981). Goal setting and task performance: 1969-1980. Psychological Bull, 90(1), 125-152.

doi: $10.1037 / 0033-2909.90 .1 .125$

Lou, P.-F. (1997). The QS 9000 quality system in Taiwan. Master Thesis, Department of Business Administration, Soochow University. 
Madu, C.N. (1998). An empirical assessment of quality: research considerations. International Journal of Quality Science, 3(4), 348-355. doi: $10.1108 / 13598539810243630$

Mellat Parast, M. (2006). The effect of quality management practice on operational and business results in the petroleum industry in Iran. PhD Thesis, The Graduate College at the University of Nebraska.

Prahalad, C.K., \& Hamel, G. (1990). The core competence of the organization. Harvard Business Review, 68(3), 79-93.

Rao, S.S., Raghunathan, T.S., \& Solis, L.E. (1997). Does IS0 9000 have an effect on quality management practices? An international empirical study. Total Quality Management, 8(6), 335-346.

Russo, M.V., \& Fouts, P.A. (1997). A resource-based perspective on corporate environmental performance and profitability. Academy of Management Journal, 40(3), 534-559.

doi: $10.2307 / 257052$

Schendel, D. (1994). Introduction to competitive organizational behavior: toward an organizationally based theory of competitive advantage. Strategic Management Journal, 15(S1), 1-4.

doi: 10.1002/smj.4250150901

Shih, L.-H., Huarng, F., \& Lin, B. (1996). ISO in Taiwan: a survey. Total Quality Management, 7(6), 681-690.

doi: $10.1080 / 09544129610568$

Sila, I. (2007). Examining the effects of contextual factors on TQM and performance through the lens of organizational theories: An empirical study. J ournal of Operations Management, 25(1), 83-109.

doi: 10.1016/j.jom.2006.02.003

Yeung, A.D.L., Cheng, T.C.E., \& Lai, K.H. (2005). An empirical model for managing quality in the electronics industry. Production and Operations Management, 14(2), 189-204.

doi: 10.1111/j.1937-5956.2005.tb00018.x 
Journal of Industrial Engineering and Management, 2010 (www.jiem.org)

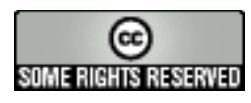

Article's contents are provided on a Attribution-Non Commercial 3.0 Creative commons license. Readers are allowed to copy, distribute and communicate article's contents, provided the author's and Journal of Industrial Engineering and Management's names are included. It must not be used for commercial purposes. To see the complete license contents, please visit http://creativecommons.org/licenses/by-nc/3.0/. 